\title{
Effectiveness of 5-Fluorouracil 5\% Cream in Perianal Condylomata Accuminata Treatment: A Case Report
}

\author{
Dea Florensia, Lita Setyowatie \\ Department of Dermatology and Venereology \\ Faculty of Medicine Universitas Brawijaya/Dr. Saiful Anwar General Hospital, Malang, Indonesia
}

\begin{abstract}
Background: Condylomata accuminata is a sexually transmitted disease, appeared as verrucous or cauliflower-like papules or warts in the anogenital. It is caused by human papillomavirus (HPV), mostly type 6 and 11. The ideal therapy should be simple, inexpensive, effective, does not cause side effects, and can be used by the patient himself. Purpose: To assess the effectiveness of 5Fluorouracil (5-FU) 5\% cream therapy for perianal condylomata accuminata treatment. Case: A 24-year-old male presented with a chief complaint of warts around the anal area that multiplied in the past 3 weeks. The acetowhite test was positive. The patient was diagnosed with condylomata accuminata perianal. The patient received 5-FU 5\% cream, applied 3 times a week to the lesions for 5 weeks. After 5 weeks, no new warts were found. Discussion: 5 -FU 5\% cream is a therapeutic option for perianal wart lesions that easily applied, inexpensive, effective, does not cause side effects, and can be used by the patient himself. It is well known as an antimetabolite with a cytotoxic effect that occurs through a mechanism of disruption in the normal synthesis and function of deoxyribonucleic acid (DNA) and ribonucleic acid (RNA). The treatment with 5-FU 5\% cream 3 times a week for 5 weeks provided good results with no side effects were reported. Conclusion: The application of 5-FU 5\% cream was a modality of self-application treatment that effective for perianal condylomata accuminata.
\end{abstract}

Keywords: condylomata accuminata, perianal, 5-Fluorouracil 5\% cream.

Correspondence: Dea Florensia, Departement of Dermatology-Venereology, Dr. Saiful Anwar General Hospital, School of Medicine Brawijaya University, Jaksa Agung Soeprapto No. 2 Malang 65111, East Java, Indonesia. Telephone: +6281233520092, e-mail:drdeaflorensia@gmail.com.

\section{BACKGROUND}

Condylomata accuminata (CA) or genital warts, is a sexually transmitted infection characterized by tumors, typically present as skin-colored warts or cauliflower-like appearance that can appear throughout the anogenital areas. Condylomata accuminata is generally caused by HPV serotype 6 or 11, but it can also be caused by HPV type 16, 18, 31, or 33 related to malignancy. ${ }^{1}$

It is estimated that around 500,000 to $1,000,000$ new CA cases are diagnosed annually. ${ }^{2}$ The prevalence rate of CA in Indonesia estimated around 5-19\%. This was supported by a study conducted at the Bali Sanglah Hospital in 2015-2017, and it reported a higher prevalence in males than females. ${ }^{3}$ Men who sex with men (MSM) and transgender women have a high risk of being affected by Human Immunodeficiency Virus (HIV) and often accompanied by HPV co-infection in the anal, penis, and oral regions, including infections with high-risk HPV serotypes. ${ }^{4,5}$ Risk factors for anal HPV infection include receptive anal intercourse (RAI), smoking, immunosuppression, and numbers of sexual partners and injection drug use. High frequency of unprotected RAI contribute to increased HPV exposure in the anal epithelium and further risk for infection, ${ }^{4}$ in which HPV serotype 16 and 18 are the most common serotypes of anal HPV infection in MSM populations. ${ }^{4,5}$ Therefore, the incidence of anal cancer (squamous cells carcinoma) increases, especially in MSM with HIV. ${ }^{6}$

The ideal therapy for CA should be simple, inexpensive, effective, and does not cause side effects. ${ }^{2}$ Specific therapy is not yet available so that eradication is not maximal, causing a significant clinical problem and frequent recurrences. ${ }^{2,7}$ The standard therapies for anal warts require medical professionals to apply, such as trichloroacetic acid, $\mathrm{CO} 2$ laser, cryotherapy, and cautery. These therapies have a higher risk, may cause uncomfortable feeling, and require specific care. ${ }^{2,10}$ Some self-applied therapies are podofilotoxin creams $0.15 \%$, imiquimod $5 \%$ cream, or 5 -FU $5 \%$ cream. 5 Fluorouracil $5 \%$ is a treatment option for perianal wart lesions that easily applied, inexpensive, effective, does not cause side effects, and can be used by the patient himself. ${ }^{2,8}$

Unfortunately, 5-FU 5\% cream is not yet available in Indonesia as a ready-to-use preparation. But Nugrahaini et al. reported that genital warts on the urethra and meatus urethra treated with 5-FU cream 5\% for 2-3 times a week have resulted in complete 
resolution after 29 days and no recurrence until the $6^{\text {th }}$ month. ${ }^{2}$ We report a case of a 24 -year-old male, MSM, diagnosed with perianal CA, and he was prescribed 5FU 5\% cream with satisfying result.

\section{CASE REPORT}

A 24-year-old man came to the Dermatology and Venereology outpatient clinic, Dr. Saiful Anwar General Hospital Malang (RSSA), with a chief complaint of warts around the anus in the last 3 weeks and multiplied. No complaint of itching, pain, or easily bleeding were reported. He has had anal intercourse, more often in the last 2 months, without using condoms. He has had sexual intercourse with his friends and some strangers. He was an MSM man with multiple sexual partners, with an average sexual frequency of 2 times per week involving different sexual partners, and more often positioned as a bottom. He rarely uses condoms. The patient was not married yet and had his first anal intercourse when he was 19 years old.

The patient claimed that had never experienced a similar complaint before. Other complaints such as genital sores, discharge from the genitals, or pain in the testicles were denied. Complaints such as drastic weight loss, recurring canker sores, difficulty swallowing, prolonged coughing, or chronic diarrhea were denied. The patient worked as an office boy in a hotel and had a side job as a masseur and commercial sex worker (CSW). The patient tried to treat the wart by applying garlic, but no improvement reported.

The general examination was within normal limits. The dermatovenereological examination showed multiple hypopigmentations and skin-colored verrucous papules, vary in size in the perianal region. Acetowhite examination with 5\% acetic acid solution in the lesion showed a positive result (Figure 1B).

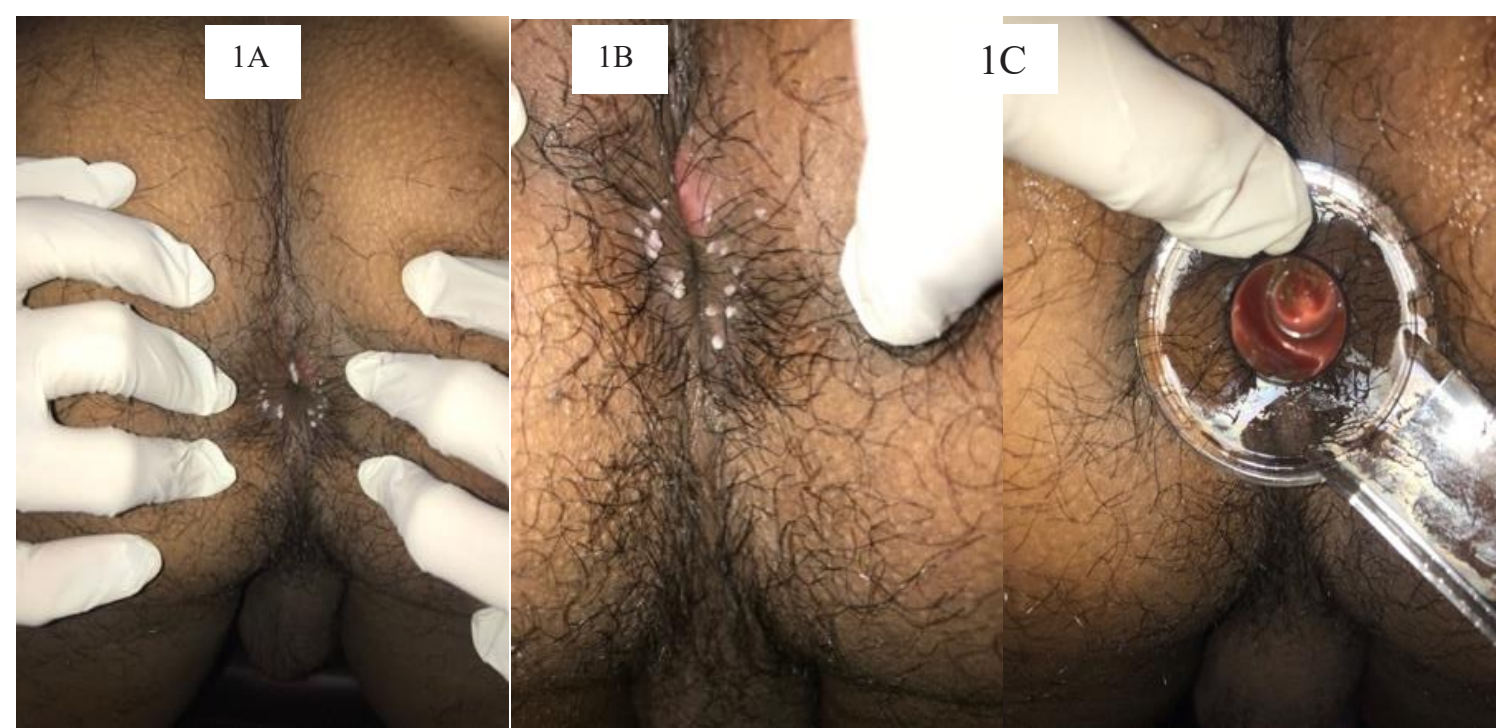

Figure 1A-B. Multiple hypopigmentations and skin-colored verrucous papules vary in size in the perianal region. Figure 1C. Anoscopy examination found no lesion in the rectal mucosa.

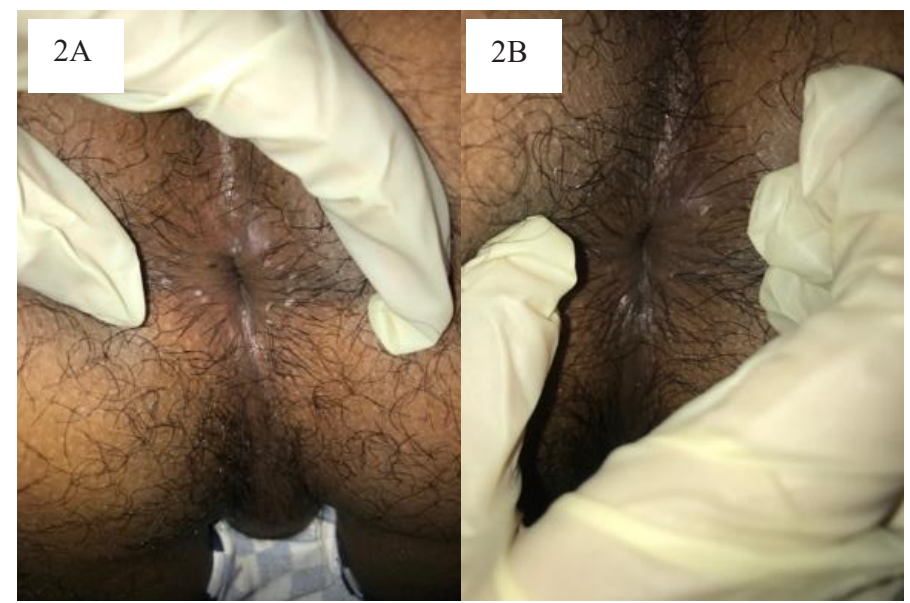

Figure 2A. In the second week, warts around the anus were decreased and shrank. The dermatovenereological examination found multiple hypopigmentations and some skin-colored verrucous papules, with vary in sizes.

Figure 2B. In the fifth week, warts around the anus disappeared. 
Laboratory test results showed a non-reactive Human Immunodeficiency Virus (HIV) rapid test, a non-reactive Venereal Disease Research Laboratory (VDRL) and a non reactive Treponema Pallidum Haemagglutination Assay (TPHA).

The patient was prescribed with 5-FU 5\% cream, applied 3 times every week to the lesion, allowed to stand for 8 hours, and then rinsed. He was encouraged to attend the follow-up visit. He has been informed about the side effects of 5-FU 5\% cream therapy, such as pain, redness, discoloration, sores, burning, itching, and swelling.

In the second week, warts around the anus were decreased and shrank. The dermatovenereological examination found multiple hypopigmentations and some skin-colored verrucous papules, with vary in sizes. The patient denied any side effects, such as sore or itchy lesions. In the fifth week, warts around the anus disappeared. The patient denied any new warts and side effects such as sore or itchy lesions.

\section{DISCUSSION}

Condylomata accuminata (CA) or genital wart is a sexually transmitted infection characterized by tumors, typically present as skin-colored warts or cauliflower-like appearance that can appear throughout the anogenital areas, and it is caused by certain serotypes of Human Papilloma Virus (HPV). ${ }^{1}$ It is estimated that around 500,000 to 1,000,000 new CA cases are diagnosed annually. ${ }^{2}$ The prevalence of $\mathrm{CA}$ in Indonesia was around 5-19\%. A study conducted at the Sanglah Hospital in Bali in 20152017 reported increased prevalence and a higher prevalence in males than females. ${ }^{3}$ The incidence ratio of males and females was 1: 1.4. ${ }^{1}$ The peak age of incidence was 24 years in females and 25-29 years in males. ${ }^{9}$ The prevalence of HPV infection continues to increase, and it is associated with a younger at first sexual intercourse as well as an increase in nonexclusive relationships (multiple sexual partners). ${ }^{1,10}$ In this case, the patient was 24 years old man, came with a chief complaint of warts around the anal in the last 3 weeks ago and multiplied. There was no itching, pain, or easily bleed. He had unprotected sexual intercourse about 2 weeks before came to the Dermatology and Venereology outpatient clinic, Dr. Saiful Anwar Malang. The patient denied if he ever had a similar complaint before. The patient was unmarried and had his first sexual intercourse at 19 years old.

Men who sex with men and transgender women have a high risk of HIV infection with more often HPV co-infection in the anal region. ${ }^{4,11}$ The prevalence of anal HPV infection is very high, about $57 \%$ on HIVnegative MSM men, and the prevalence increased 60 folds in HIV-positive MSM men compared to the normal male population. ${ }^{10}$

Risk factors for anal HPV infection include receptive anal intercourse (RAI), smoking, immunosuppression, multiple sexual partners, and injection drug use. High frequency of unprotected RAI contribute to an increase in anal HPV exposure in the anal epithelium and further infection risk. ${ }^{4,11}$ In the western population, there have been reports that the most common types of anal HPV infection in MSM populations are HPV serotypes 16 and $18 .^{5,11}$ Therefore, the incidence of anal cancer increases, known as squamous cell carcinoma, especially in MSM with HIV. Furukawa et al. reported a high risk of serotype HPV with high grade squamous intraepithelial lesion (HSIL) leading to anal cancer from the anal CA tissue specimens in HIV-positive MSM patients in Japan. ${ }^{6}$ In this case, the patient has a high-risk factor for anal CA in consideration of his sexual behavior. The patient was a bottom MSM, having an average of 2 sexual intercourse per week with multiple sexual partners and rarely used condoms. He worked as a CSW, had an early age of first sexual intercourse, and he was a smoker.

The diagnosis of CA is based on history taking and clinical features, including additional testing with acetic acid and anoscopy. ${ }^{10}$ The transmission of HPV infection is mainly through sexual contact, but there are reports on mother-to-child transmission, although the pathogenesis is not yet clearly known. The time interval between infection and the first appearance of CA is around 3-8 weeks. ${ }^{10}$ The clinical feature of warts in the anal part is flat or erythematous plaque or plaque with the location of the infected area. ${ }^{11}$ Lesions are rarely felt with severe symptoms but are sometimes accompanied by anal discomfort and pruritus. ${ }^{10}$ In this case, the diagnosis of CA is based on history taking, dermatovenereological examination, diagnostic test with acetowhite examination, and anoscopy. The dermatovenereoogical examination found multiple hypopigmentations and some skin-colored verrucous papules, vary in sizes. The clinical features of this patient were in accordance with the CA.

Acetowhite examination is an examination of HPV lesions using 3-5\% acetic acid, where the lesion will turn grayish-white, caused by excessive expression of cytokeratin-10 (CK10) in suprabasal cells infected with HPV. These cells are undifferentiated and contain high protein, and whitish color comes from denaturation. However, this examination has a low sensitivity and specificity value. ${ }^{12}$ Acetowhite examination of this patient showed a positive result. 
Men who sex with men patients have a higher risk of several infectious conditions, including HIV and other sexually transmitted infections, Kaposi's sarcoma, viral hepatitides, methicillin-resistant skin infections Staphylococcus aureus, and invasive meningococcal diseases. They may also have a high risk of several non-infectious conditions such as skin cancer. MSM patients are known to have a higher prevalence of anal, penile, and oral HPV infections, including infections with high-risk HPV serotypes. ${ }^{5}$ Laboratory tests on these patients showed a nonreactive result on HIV rapid test and a non-reactive result on VDRL / TPHA.

The main goal of the treatment of CA is to remove wart lesions, reduce the psychological stress caused by $\mathrm{CA}$, and prevent a recurrency. About $10 \%-30 \%$ of CA are usually limited to immunocompetent individuals and can self-healed about 12-24 months if not treated. Several cases of recurrence were associated with HPV 11 infection. $^{9}$

Some factors that influence the selection of therapeutic modalities are the size of the lesion, location, type and number of lesions, the patient's ability to apply therapy, the price of the drug, and the doctor's skills. ${ }^{9,10}$ Ideal therapy for CA should be easily applied, inexpensive, effective, and does not cause side effects. ${ }^{2,13}$ Specific therapy is not yet available so that eradication is not maximal, causing a significant clinical problem and frequent recurrences. ${ }^{2,7}$ The therapeutic plan for anal warts can be classified as patient-applied therapies such as perianal warts, and therapies that require medical professionals such as for intra-anal or rectal mucosal lesions. ${ }^{10,14}$ Some selfapplied therapies are podofilotoxin creams $0.15 \%$, imiquimod $5 \%$ cream, or 5 -FU $5 \%$ cream. Therapies that require medical professionals to apply are trichloroacetic acid, CO2 laser, cryotherapy, and cautery. These therapies have a higher risk, may cause an uncomfortable feeling, and require specific care..$^{2,15}$

5 -Fluorouracil 5\% cream is a therapeutic option for perianal wart lesions, and it is well known as an antimetabolite with a cytotoxic effect that occurs through a mechanism of disruption in the normal synthesis and function of DNA and ribonucleic acid (RNA). The use of 5-FU 5\% cream in mucosal lesions is not recommended because it causes local inflammation and ulceration. ${ }^{12}$

Nugrahaini et al. reported that genital warts on the urethra and meatus urethra treated with 5-FU cream 5\% for 2-3 times a week, allowed to stand for 3-10 hours, and then rinsed, have resulted in complete response after 29 days and no recurrency until the 6th month. ${ }^{2}$ Also, a study by Krebs on 49 non-pregnant women with $\mathrm{CA}$ on the vulva, given 5 -FU cream $5 \%$ every night for 6 weeks and then continued once a week for 10 weeks, reported that $71 \%$ of patients gave a good response and $29 \%$ of patients did not respond. This study also reports that a periodic application is more recommended than a continuous application. Side effects that can occur including pain, erythema, discoloration, erosion, ulceration, burning, itching, and swelling. Another study that was conducted by Pride et al. on 19 female patients with extragenital CA given topical 5-FU for 7 days gave $68.4 \%$ of patients a complete response, and 1 patient did not respond to therapy. $^{7}$

Another study was conducted on external anogenital CA. The sample was divided into 2 groups with a simple randomization method. The first group was given 5-FU 5\% cream therapy, and the second group was given $80 \%$ TCA. There was no statistically significant difference in effectiveness between those two therapies, but less recurrence and fewer side effects were found in the group given 5 -FU $5 \%$ cream. $^{7}$ In this case, perianal CA treated with 5-FU 5\% cream 3 times a week for 5 weeks provided good results. No side effects such as pain, erythema, discoloration, erosion, ulceration, burning, itching, and swelling were reported. Therefore, 5-FU 5\% cream is an easily applied therapeutic modality and effectively reducing perianal CA lesions.

\section{REFERENCES}

1. Widyaswari MS, Lumintang $H$, Soemarno $T$. Imunohistokimia pada kondilomata akuminata. Medical and Health Science Journal 2019; 3(1): 47-54.

2. Nugrahaini PKC, Cahyawari D, Iriani J, Achdiat PA, Rowawi R. Laporan Kasus: Kutil kelamin pada uretra dan meatus uretra yang diterapi dengan Krim 5-Fluorourasil 5\%. Syifa' MEDIKA: Jurnal Kedokteran dan Kesehatan 2018; 9(1): 25-32.

3. Puspawati NMD, Sissy, Gotama D. A retrospective study of condyloma acuminata profile in the outpatient clinic of dermato-venereology Sanglah General Hospital Denpasar, Bali-Indonesia period 2015-2017. Bali Dermatol Venereol J 1 2018: 1-3.

4. Wood SM, Salas-Humara C, dan Dowshen NL. Human immunodeficiency virus, other sexually transmitted infections, and sexual and reproductive health in lesbian, gay, bisexual, transgender youth. Pediatric Clinics 2016; 63(6): 1027-55.

5. Yeung H, Luk KM, Chen SC, Ginsberg BA, Katz KA. Dermatologic care for lesbian, gay, bisexual, and transgender persons: Epidemiology, screening, and disease prevention. J Am Acad Dermatol 2019; 80(3): 591-602. 
6. Furukawa S, Uota S, Yamana T, Sahara R, Iihara $\mathrm{K}$, Yokomaku Y, et al. Distribution of Human Papillomavirus genotype in anal condyloma acuminatum among japanese men: the higher prevalence of high risk Human Papillomavirus in men who have sex with men with HIV infection. AIDS Res Hum Retroviruses 2018; 34(4): 375-81.

7. Werner RN, Westfechtel L, Dressler C, Nast A. Anogenital warts and other HPV-associated anogenital lesions in the HIV-positive patient: a systematic review and meta-analysis of the efficacy and safety of interventions assessed in controlled clinical trials. Sex Transm Infect 2017; 93(8): 543 550.

8. Gilson R, Nugent D, Werner RN, Ballesteros J, Ross J. 2019 IUSTI-Europe guideline for the management of anogenital warts. J Eur Acad Dermatol Venereol 2020; 34(8): 1644-53.

9. Andriani, Indah, dan Dwi Puspawati. Terapi kombinasi zink oral dan asam trikloroasetat $80 \%$ pada giant kondiloma akuminata perianal. MEDICINA 2018; 49(3): 399-406.

10. Leszczyszyn J, Lebski I, Lynsenko L, Hirnle L, Gerber H. Anal warts (condylomata acuminata)- current issues and treatment modalities." Adv Clin Exp Med 2014; 23(2): 307-11.

11. Cranston RD, Carballo-Dieguez A, Gundacker H, Richardson BA, Giguere R, Dolezal C, et al. Prevalence and determinants of anal human papillomavirus infection in men who have sex with men and transgender women. Int J STD AIDS 2019; 30(2): 154-162.

12. Ceilley RI. Mechanisms of action of topical 5fluorouracil: review and implications for the treatment of dermatological disorders. J Dermatolog Treat 2012; 23(2): 83-9.

13. Choi, Hoon. Can quadrivalent human papillomavirus prophylactic vaccine be an effective alternative for the therapeutic management of genital warts? an exploratory study. Int Braz J Urol 2019; 45(2): 361-8.

14. Clanner-Engelshofen BM, Marsela E, Engelsberger N, Guertler A, Schauber J, French LE, Reinholz M. Condylomata acuminata: A retrospective analysis on clinical characteristics and treatment options. Heliyon 2020; 6(3): 1-7.

15. Wiraguna, A., Puspawati, N. 2020. Condyloma acuminatum in a 62-year-old patient with HIV infection. Bali Medical Journal 2020; 9(1): 91-4. 